Material London, ca. I600 


\section{NEW CULTURAL STUDIES}

Series Editors

Joan DeJean

Carroll Smith-Rosenberg

Peter Stallybrass

Gary A. Tomlinson

A complete list of books in the series

is available from the publisher. 


\title{
Material London, ca. 1600
}

\section{Edited by Lena Cowen Orlin}

\author{
PENN \\ University of Pennsylvania Press \\ Philadelphia
}


Copyright (C) 2000 University of Pennsylvania Press

All rights reserved

Printed in the United States of America on acid-free paper

IO $98765432 \mathrm{I}$

Published by

University of Pennsylvania Press

Philadelphia, Pennsylvania I9104-40I I

Library of Congress Cataloging-in-Publication Data

Material London, ca. I600 / edited by Lena Cowen Orlin.

p. $\quad \mathrm{cm} .-$ (New cultural studies)

Includes bibliographical references and index.

ISBN 0-8I 22-3540-I (cloth : alk. paper). - ISBN 0-8122-172I-7 (pbk. : alk. paper)

I. London (England) - History - I6th century. 2. London (England) -- history - I 7 th century. 3. Material culture-England - London. I. Title: Material London, ca. I60o. II. Orlin, Lena Cowen. III. Series.

DA680.M38 2000

942.IO5's-de2I

99-054378 